\title{
Decoupled Model for Asymmetrical Dual Three Phase Permanent Magnet Synchronous Machine
}

\author{
Yuzheng Chen \\ University of Nottingham \\ Nottingham, United Kingdom \\ yuzheng.chen@nottingham.ac.uk \\ Serhiy Bozhko \\ University of Nottingham \\ Nottingham, United Kingdom \\ serhiy.bozhko@nottingham.ac.uk
}

\author{
Linhui Fan \\ University of Nottingham \\ Nottingham, United Kingdom \\ linhui.fan@nottingham.ac.uk \\ Tao Yang \\ University of Nottingham \\ Nottingham, United Kingdom \\ tao.yang@nottingham.ac.uk
}

\author{
M. Raza Khowja \\ University of Nottingham \\ Nottingham, United Kingdom \\ raza.khowja@nottingham.ac.uk
}

\begin{abstract}
This paper presents a decoupled modeling method for asymmetrical dual three phase (DTP) permanent magnet synchronous machine (PMSM). Due to the special structure of this machine, traditional decoupled method cannot be applied on it. This paper proposes a new method that applying inverse voltage to two sets of windings and transferring 6 phase model to a symmetrical 3 phase model, which d-q decoupled control can be used. Simulation result shows the equivalent symmetrical model has exact the same dynamic and steady performance with the asymmetrical dual three phase model.
\end{abstract}

Keywords-Dual Three Phase (DTP) PMSM, Decoupled Model, Asymmetrical Machine, Diagonal Matrix

\section{INTRODUCTION}

More electric aircraft (MEA) has become a trend for its great advantages such as low $\mathrm{CO}_{2}$ emission, low noise, high reliability and etc. In this paper, a dual three phase (DTP) PMSM is investigated as starter-generator for aircraft propeller. The DTP-PMSM is installed on the propeller shaft like Fig. 1. It operates as motor during engine-starting period and then switches to generator mode after engine starts.

DTP-PMSM has two star-connected three-phase stator windings with isolated neutral point. In general, windings in one 3-phase are always alternated along the stator circumference with equal interval [1], [2], but the machine mentioned in this paper is different as each set of windings is placed only on half of stator. Most research about DTP machine before is about symmetrical windings distribution, even some papers researching asymmetrical windings have no similarity with this machine[3]-[5].

The bearingless multisector PMSM is researched in [6][9], which divides the stator into 3 parts equally. This structure is very similar with the DTP machine in this paper but their interest is on the math model and control algorithm between radial force and currents. The relationship between voltage and current doesn't be discussed.

This paper is organized as follow: section II presents the asymmetrical windings distribution (Part A), asymmetrical inductance matrix (Part B), dual three phase asymmetrical model (Part C) and equivalent XYZ symmetrical model (Part D) of the machine, section III proves the equivalence of two machine model; section IV compare the XYZ model with dual 3 phase model in PLECS and with finite element model in MagNet; section V is conclusion.

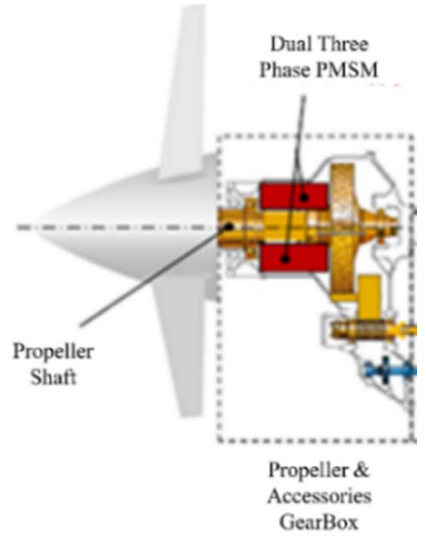

Fig. 1. Application background

\section{DuAl Three Phase Machine Model}

\section{A. Asymmetrical windings distribution of Dual Three Phase Machine}

Fig. 2 shows the structure of stator and rotor which has 18 slots and 12 poles. The winding connection and permanent magnet direction are labelled on the figure, showing the machine is split into two parts and each 3-phase windings occupies half of stator.

This kind of winding distribution is specifically designed for fault-tolerant machine, which should have the properties of electrical separation, magnetic separation and physical separation [10]. Splitting stator into 2 parts can achieve minimum mutual inductance between the two 3-phase windings. This design is for magnetic separation, which exhibits lower short circuit current and higher average torque when one 3-phase windings is short-circuit [11], [12].

\section{B. Asymmetrical Inductance Matrix of Dual Three Phase Machine}

The symmetrical 3-phase windings should be alternated along the stator circumference with same interval. However, each 3-phase windings is only displaced on half of the stator, which makes symmetrical displacement impossible. Inductance matrix for 6 windings is calculated from MagNet and listed in Table I. Equation (1) divides Table I to 4 parts, $\boldsymbol{L}$ represents the self and mutual inductance within each set of windings, and $\boldsymbol{M}$ represents the mutual inductance between two sets. Both of them are $3 \times 3$ matrixes. 


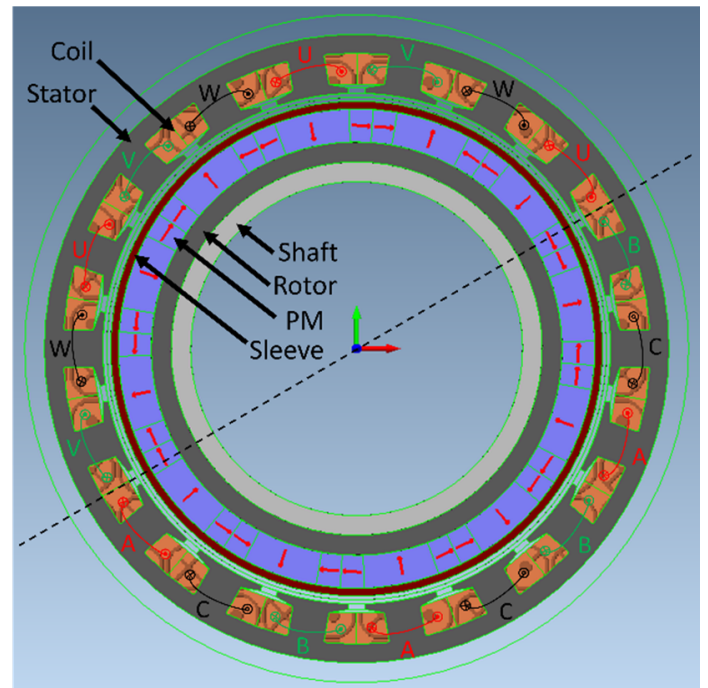

Fig. 2. Structure of Dual Three Phase Machine

$$
L_{s}=\left[\begin{array}{cc}
\boldsymbol{L} & \boldsymbol{M} \\
\boldsymbol{M} & \boldsymbol{L}
\end{array}\right]_{6 \times 6}
$$

TABle I. InduCtance MAtrix From MagNet $(\mu H)$

\begin{tabular}{|c|c|c|c|c|c|c|}
\hline & $\mathbf{A}$ & $\mathbf{B}$ & $\mathbf{C}$ & $\mathbf{U}$ & $\mathbf{V}$ & $\mathbf{W}$ \\
\hline $\mathbf{A}$ & 326 & -81 & -111 & 20 & 50 & 20 \\
\hline $\mathbf{B}$ & -81 & 326 & -111 & 50 & 20 & 20 \\
\hline $\mathbf{C}$ & -111 & -111 & 326 & 20 & 20 & 20 \\
\hline $\mathbf{U}$ & 20 & 50 & 20 & 326 & -81 & -111 \\
\hline $\mathbf{V}$ & 50 & 20 & 20 & -81 & 326 & -111 \\
\hline $\mathbf{W}$ & 20 & 20 & 20 & -111 & -111 & 326 \\
\hline
\end{tabular}

For a symmetrical dual three phase machine, both $\boldsymbol{L}$ and $\boldsymbol{M}$ should have one value for diagonal line items and another value for non-diagonal items, but $\boldsymbol{L}$ and $\boldsymbol{M}$ don't meet that standard (e.g., $M_{A B} \neq M_{A C}, M_{A V} \neq M_{A W}$ ). The reason why $M_{A B}$ is smaller than $M_{A C}$ is that windings A, C are always next to each other but $\mathrm{A}, \mathrm{B}$ are discontinuous near the boundary of two 3-phase windings. If the mutual inductances in one 3phase windings are not equal, it cannot be transferred to diagonal matrix by Clarke-Park transformation, which means decoupled d-q current control is impossible.

\section{Dual Three Phase Asymmetrical Model of Machine}

Equations (2) and (3) are the voltage and flux linkage expression, and corresponding symbols are defined in (1),(4)(9), in which all vectors are divided to two parts. The vectors with subscript " 1 " represent the variables of $\mathrm{ABC}$ windings, and the vectors with subscript " 2 " represent the variables of UVW windings.

$$
\begin{aligned}
& \boldsymbol{u}_{\mathbf{s}}=R \boldsymbol{i}_{s}+\frac{d \phi_{s}}{d t} \\
& \phi_{s}=L_{s} i_{s}+\phi_{m} \lambda \\
& \boldsymbol{u}_{\boldsymbol{s}}=\left[\begin{array}{l}
\boldsymbol{u}_{1} \\
\boldsymbol{u}_{2}
\end{array}\right]=\left[\begin{array}{lllll}
u_{a} & u_{b} & u_{c} \mid u_{u} & u_{v} & u_{w}
\end{array}\right]^{T} \\
& \boldsymbol{i}_{\boldsymbol{s}}=\left[\begin{array}{l}
\boldsymbol{i}_{1} \\
\boldsymbol{i}_{2}
\end{array}\right]=\left[\begin{array}{lllll}
i_{a} & i_{b} & i_{c} \mid i_{u} & i_{v} & i_{w}
\end{array}\right]^{T} \\
& \boldsymbol{\phi}_{s}=\left[\begin{array}{l}
\phi_{1} \\
\boldsymbol{\phi}_{2}
\end{array}\right]=\left[\begin{array}{lllll}
\phi_{a} & \phi_{b} & \phi_{c} \mid \phi_{u} & \phi_{v} & \phi_{w}
\end{array}\right]^{T}
\end{aligned}
$$

$$
\begin{gathered}
\lambda=\left[\begin{array}{l}
\lambda_{1} \\
\lambda_{2}
\end{array}\right] \\
\lambda_{1}=\left[\begin{array}{lll}
\cos (\theta) & \cos \left(\theta-\frac{2 \pi}{3}\right) & \cos \left(\theta+\frac{2 \pi}{3}\right)
\end{array}\right]^{T} \\
\lambda_{2}=\left[\begin{array}{lll}
\cos (\theta-\pi) & \cos \left(\theta+\frac{\pi}{3}\right) & \cos \left(\theta-\frac{\pi}{3}\right)
\end{array}\right]^{T}
\end{gathered}
$$

Substituting (3) into (2), the voltage expression is like (10). Because the permanent magnet of the machine is surface mounted, the stator inductance won't change with rotor position and the derivation of $\boldsymbol{L}_{\boldsymbol{S}}$ is zero.

$$
\boldsymbol{u}_{\mathbf{s}}=R \boldsymbol{i}_{\boldsymbol{s}}+\boldsymbol{L}_{\boldsymbol{s}} \frac{d i_{s}}{d t}+\phi_{m} \frac{d \lambda}{d t}
$$

\section{Equivalent Three Phase Symmetrical Model of Machine (XYZ Model)}

Due to $\boldsymbol{L}_{\boldsymbol{S}}$ cannot be diagonalized using Clarke-Park transformation, an equivalent three phase symmetrical model (XYZ model in Fig. 3) is introduced here to achieve decoupled control. In fact, the dual three phase machine can be transferred to a traditional three phase machine by inversely cascading $\mathrm{U} / \mathrm{V} / \mathrm{W}$ windings with $\mathrm{A} / \mathrm{B} / \mathrm{C}$ windings separately. If the labels " $\mathrm{U} / \mathrm{V} / \mathrm{W}$ " in Fig. 2 are replaced by " $\mathrm{A} / \mathrm{B} / \mathrm{C}$ ", $\mathrm{A} / \mathrm{B} / \mathrm{C}$ windings are alternated along the stator circumference with same interval just like the windings distribution of a three phase machine.

Therefore, this part discusses how to obtain XYZ math model under the assumption of cascading two 3-phase windings together, and next section will discuss under what condition the windings can be regarded as cascaded.

Fig. 4 is an example to show how to determine the mutual inductance $M_{X Y}$ from dual three phase model. In fact, because windings $\mathrm{A}$ and $\mathrm{U}$ (same with $\mathrm{B}$ and $\mathrm{V}$ ) are regarded as cascaded, $M_{X Y}$ should include mutual inductance not only between $A \& B$, but also $A \& V, U \& B$ and $U \& V$. Table II shows the inductance matrix of $\mathrm{XYZ}$ model which is derived from Table I by using (11). It's amazing $\boldsymbol{L}_{X Y Z}$ is a symmetrical matrix, just like the traditional three phase surface mounted permanent magnet machine.

$$
\boldsymbol{L}_{X Y Z}=2(\boldsymbol{L}-\boldsymbol{M})
$$

The voltage equation of XYZ model is shown in (12), in which $\lambda_{\sin }$ is defined as (13). The coefficient " 2 " before $R$ and $\phi_{m}$ is due to the cascade of windings. Appling ClarkePark transformation to (12), the decoupled XYZ model (d-q model) is obtained like (14), in which $L_{D}$ and $L_{Q}$ are calculated from $\boldsymbol{L}_{\boldsymbol{X Y Z}}$ and listed in Table III. The phase resistance and no-load flux linkage obtained from MagNet are also listed in Table III.

$$
\begin{gathered}
{\left[\begin{array}{l}
u_{X} \\
u_{Y} \\
u_{Z}
\end{array}\right]=2 R\left[\begin{array}{l}
i_{X} \\
i_{Y} \\
i_{Z}
\end{array}\right]+\boldsymbol{L}_{X Y Z}\left[\begin{array}{l}
i_{X} \\
i_{Y} \\
i_{Z}
\end{array}\right]^{\prime}-\omega_{e} 2 \phi_{m} \lambda_{\sin }} \\
\lambda_{\sin }=\left[\sin (\theta) \quad \sin \left(\theta-\frac{2 \pi}{3}\right) \sin \left(\theta+\frac{2 \pi}{3}\right)\right]^{T} \\
{\left[\begin{array}{l}
\tilde{u}_{d} \\
\tilde{u}_{q}
\end{array}\right]=2 R\left[\begin{array}{l}
\tilde{l}_{d} \\
\tilde{l}_{q}
\end{array}\right]+\left[\begin{array}{cc}
L_{D} & 0 \\
0 & L_{Q}
\end{array}\right]\left[\begin{array}{l}
\tilde{l}_{d} \\
\tilde{l}_{q}
\end{array}\right]^{\prime}+\omega_{e}\left[\begin{array}{c}
-L_{Q} \tilde{\imath}_{q} \\
L_{D} \tilde{\imath}_{d}+2 \phi_{m}
\end{array}\right]}
\end{gathered}
$$


TABLE II. INDUCTANCE MATRIX FOR XYZ MODEL $(\mu H)$

\begin{tabular}{|c|c|c|c|}
\hline & $\mathbf{X}$ & $\mathbf{Y}$ & $\mathbf{Z}$ \\
\hline $\mathbf{X}$ & 612 & -262 & -262 \\
\hline $\mathbf{Y}$ & -262 & 612 & -262 \\
\hline $\mathbf{Z}$ & -262 & -261 & 612 \\
\hline
\end{tabular}
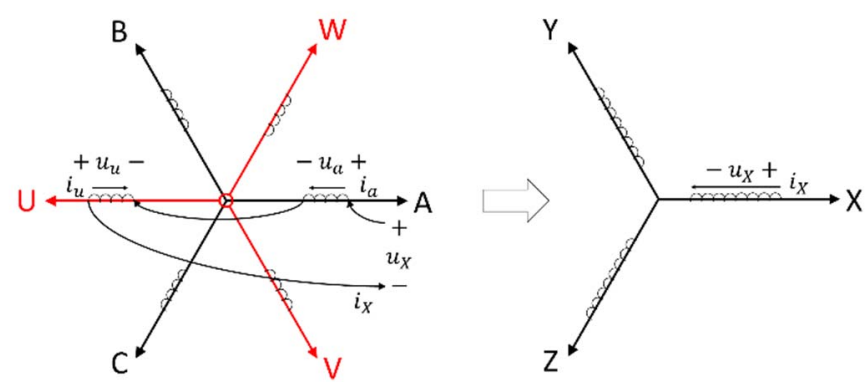

Fig. 3. The Equivalent Relation Between XYZ Model and Dual Three Phase Model
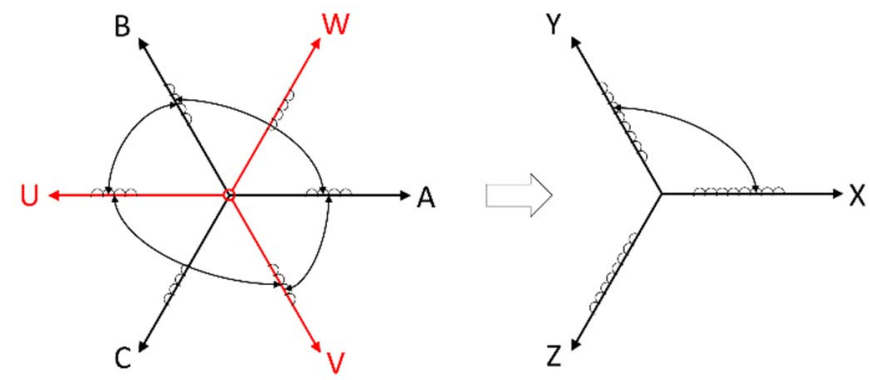

Fig. 4. Determination of Mutual Inductance Between Winding X and Y

TABLE III. PARAMETERS OF MACHINE

\begin{tabular}{|c|c|c|}
\hline Parameter & Mark & Value \\
\hline Phase Resistance & $R$ & $0.035 \Omega$ \\
\hline Peak No-load Flux Linkage per channel & $\phi_{m}$ & $0.033 \mathrm{Vs}$ \\
\hline d-/q-axis Inductance for XYZ Model & $L_{D} / L_{Q}$ & $874 \mu \mathrm{H}$ \\
\hline Pole numbers & $\mathrm{P}$ & 12 \\
\hline
\end{tabular}

\section{Proof of Equivalence Between Two Models}

This section proves that if inversed voltage is given to two sets of windings, even the initial currents of two sets are different, their magnitudes will change to the same rapidly. Although it's impossible to cascading two sets physically, it can be regarded as virtually cascaded if current magnitudes are equal.

Substituting (1),(4)-(9) to (10), the voltage expression becomes (15), in which $\lambda_{\sin }$ is defined as (13).

$$
\left[\begin{array}{l}
\boldsymbol{u}_{1} \\
\boldsymbol{u}_{2}
\end{array}\right]=R\left[\begin{array}{l}
\boldsymbol{i}_{1} \\
\boldsymbol{i}_{2}
\end{array}\right]+\left[\begin{array}{cc}
\boldsymbol{L} & \boldsymbol{M} \\
\boldsymbol{M} & \boldsymbol{L}
\end{array}\right]\left[\begin{array}{l}
\boldsymbol{i}_{1} \\
\boldsymbol{i}_{2}
\end{array}\right]^{\prime}-\omega_{e} \phi_{m}\left[\begin{array}{c}
\lambda_{\sin } \\
-\lambda_{\sin }
\end{array}\right]
$$

If adding the first line and the second line of (15) together, the item with $\omega_{e} \phi_{m}$ will be eliminated and it becomes (16), in which $\boldsymbol{i}_{\boldsymbol{m}}$ is defined as (17)

$$
\begin{gathered}
\boldsymbol{u}_{1}+\boldsymbol{u}_{2}=R \boldsymbol{i}_{\boldsymbol{m}}+(L+M) \boldsymbol{i}_{\boldsymbol{m}}^{\prime} \\
\boldsymbol{i}_{\boldsymbol{m}}=\boldsymbol{i}_{1}+\boldsymbol{i}_{2}
\end{gathered}
$$

If inversed voltage like (18) is applied, the expression of $\boldsymbol{i}_{\boldsymbol{m}}$ can be obtained as (19), which is a first order homogeneous linear differential equations. Equation (20) is the solution of
(19), in which $c_{1}, c_{2}, c_{3}$ are coefficients determined by initial condition, $\lambda_{1}, \lambda_{2}, \lambda_{3}$ are the eigenvalues of (21) and $\boldsymbol{r}_{\mathbf{1}}, \boldsymbol{r}_{\mathbf{2}}, \boldsymbol{r}_{\mathbf{3}}$ are the eigenvectors of (21). The matrix $\boldsymbol{A}$ is defined in (22).

$$
\begin{gathered}
\boldsymbol{u}_{2}=-\boldsymbol{u}_{\mathbf{1}} \\
\boldsymbol{i}_{\boldsymbol{m}}^{\prime}=-R(\boldsymbol{L}+\boldsymbol{M})^{-1} \boldsymbol{i}_{\boldsymbol{m}} \\
\boldsymbol{i}_{\boldsymbol{m}}=c_{1} e^{\lambda_{1} t} \boldsymbol{r}_{\mathbf{1}}+c_{2} e^{\lambda_{2} t} \boldsymbol{r}_{\mathbf{2}}+c_{3} e^{\lambda_{3} t} \boldsymbol{r}_{\mathbf{3}} \\
(\boldsymbol{A}-\lambda \boldsymbol{E}) \boldsymbol{r}=0 \\
\boldsymbol{A}=-R(\boldsymbol{L}+\boldsymbol{M})^{-1}
\end{gathered}
$$

Using the machine parameters listed in Table I and Table III, the eigenvalues and eigenvectors can be calculated out like (23) and (24)

$$
\begin{gathered}
\left\{\begin{array}{l}
\lambda_{1}=-2279 \\
\lambda_{2}=-1221 \\
\lambda_{3}=-1000
\end{array}\right. \\
\left\{\begin{array}{lll}
\boldsymbol{r}_{1}=\left[\begin{array}{lll}
-0.5286 & -0.5295 & -0.6635
\end{array}\right]^{T} \\
\boldsymbol{r}_{2}=\left[\begin{array}{lll}
0.7063 & -0.7079 & 0.0021
\end{array}\right]^{T} \\
\boldsymbol{r}_{3}=\left[\begin{array}{lll}
-0.4708 & -0.4675 & 0.7482
\end{array}\right]^{T}
\end{array}\right.
\end{gathered}
$$

Fig. 5 and Fig. 6 are the dynamic waveforms of $\boldsymbol{i}_{\boldsymbol{m}}$ with different initial conditions. Both of them show $\boldsymbol{i}_{\boldsymbol{m}}$ will reduce to zero quickly, which means currents of two sets of windings will have equal magnitude and inversed direction like (25). Therefore, it can be regarded U/V/W windings are inversely cascaded with $\mathrm{A} / \mathrm{B} / \mathrm{C}$ windings if voltage like (18) is applied.

$$
\left\{\begin{array}{l}
i_{a}=-i_{u} \\
i_{b}=-i_{v} \\
i_{c}=-i_{w}
\end{array}\right.
$$

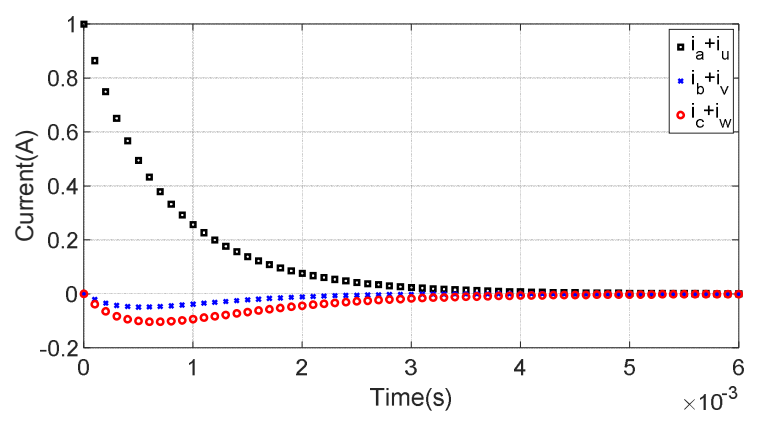

Fig. 5. Dynamic Current Waveform with Initial Condition $\boldsymbol{i}_{\boldsymbol{m} \mathbf{0}}=$ $[1.0,0.0,0.0](\mathrm{A})$

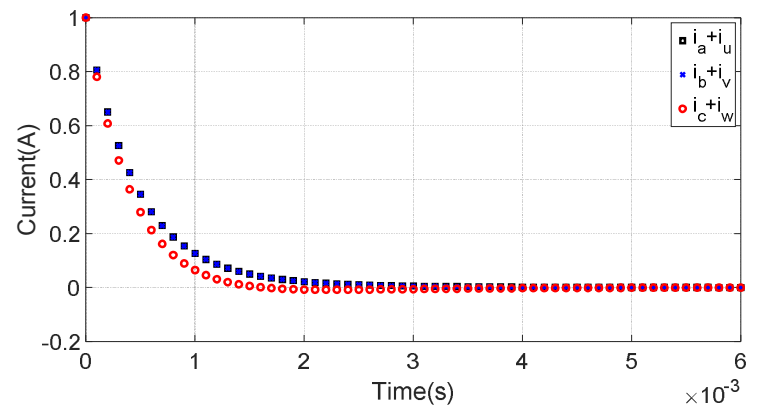

Fig. 6. Dynamic Current Waveform with Initial Condition $\boldsymbol{i}_{\boldsymbol{m} \mathbf{0}}=$ $[1.0,1.0,1.0](\mathrm{A})$ 


\section{Simulation Result}

In order to verify the equivalence of dual three phase model with XYZ model, simulation model with structure of Fig. 7 is built in PLECS. PLECS is a simulation software for power electronics system. It is very efficient to simulate machine and its control system. In Fig. 7, the "Dual 3 Phase Model" is based on (10) and use the stator inductance listed in Table I and phase resistance and peak no-load flux linkage listed in Table III. The "XYZ Model" is based on (14) with its parameters listed in Table III. Only current close loop is simulated here because the machine mechanical formula is the same for the two model. Therefore, rotor speed of the two models is set to a constant speed of $10000 \mathrm{r} / \mathrm{min}$ and $\mathrm{d}$ - and qaxis current references are set to $0 \mathrm{~A}$ and $32.3 \mathrm{~A}$ separately.

In Fig. $7, u_{d_{-} c m p}$ and $u_{q_{-} c m p}$ are the voltage compensations to achieve $\mathrm{d} / \mathrm{q}$-axis current decouple. The $\mathrm{d} / \mathrm{q}$ axis currents of dual 3 phase model are selected as feedback and XYZ model runs in open loop. The comparison of d-axis currents is shown in Fig. 8. It shows $i_{d 1}, i_{d 2}$ match well with $\tilde{l}_{d}$ and all of them are returned to $i_{d}^{*}$ rapidly. Similarly, the simulation result of q-axis current in Fig. 9 also shows $i_{q}$ of the two models matches well. Therefore, Fig. 8 and Fig. 9 prove the XYZ model is equivalent with asymmetrical dual three phase model. Fig. 10 and Fig. 11 are the six phase currents and voltages of dual 3 phase model separately.

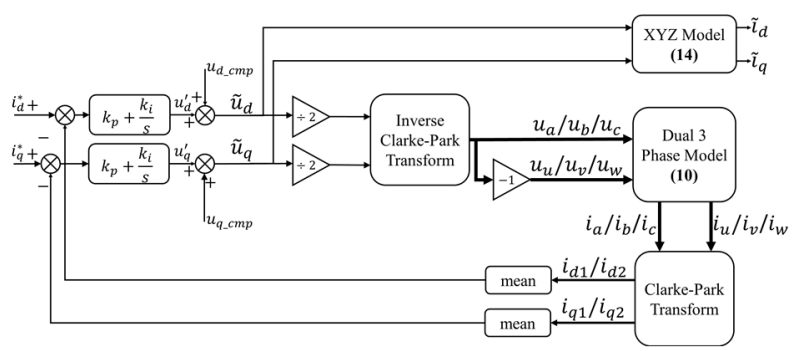

Fig. 7. PLECS simulation slgorithm structure

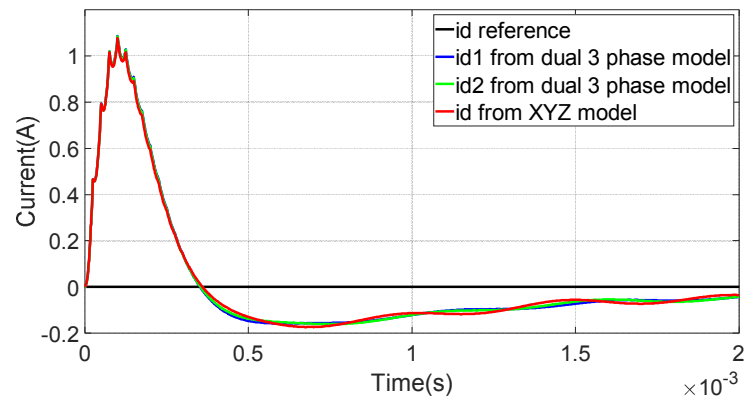

Fig. 8. Comparison of d-axis current of dual 3 phase model and XYZ model in PLECS

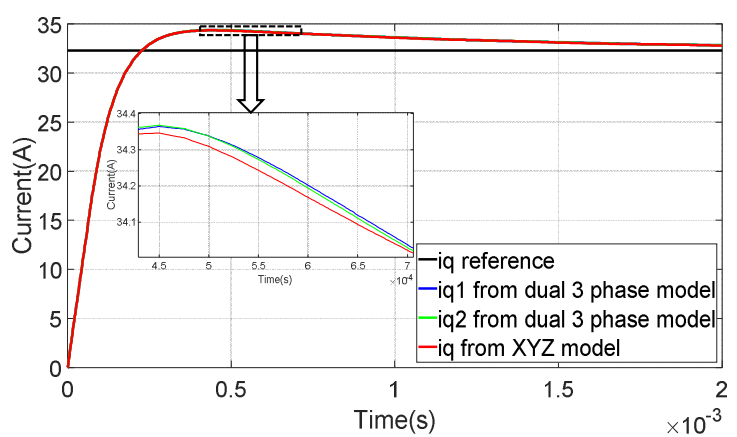

Fig. 9. Comparison of q-axis currents of dual 3 phase model and XYZ model in PLECS

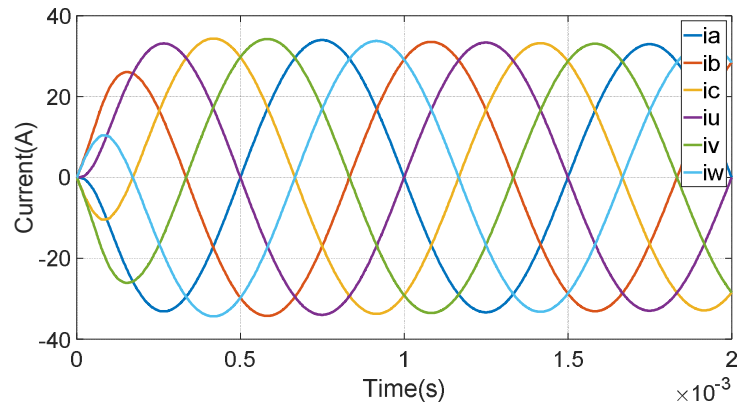

Fig. 10. Six phase currents from dual 3 phase model in PLECS

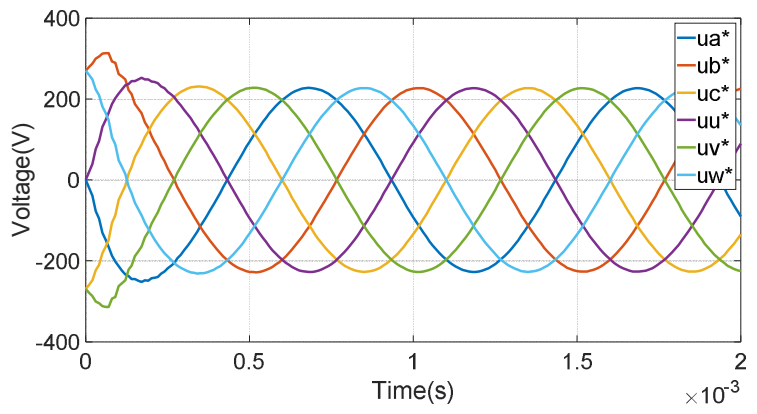

Fig. 11. Six phase voltage obtained from PLECS

In order to make the XYZ model more convincing, comparison with finite element model is done. The finite element model of machine is built in MagNet as shown in Fig. 2, which includes not only rotor and stator but also shaft and sleeve. MagNet is a famous 2D/3D electromagnetic field simulation software.

In MagNet, the rotor is set to velocity driven with 10000 $\mathrm{r} / \mathrm{min}$ and the initial position of rotor is set to 0 electrical degree just like in PLECS. The six phase windings are driven by 6 independent current sources. The waveform of these current sources are shown in Fig. 10 and they are imported from PLECS.

The six phase voltage of finite element machine model are shown in Fig. 12. Compared with the six phase voltage from PLECS (Fig. 11), obvious harmonic voltage component can be seen in Fig. 12, which is caused by the material nonlinearity. The material of stator and rotor are non-oriented silicon steel which has nonlinear magnetic permeability $(\mu)$. Therefore, it will cause magnetic flux density (B) to saturate as current is large.

If changing the material of stator and rotor to ideal silicon steel which has a constant magnetic permeability, the six phase voltage from MagNet will become more sinusoidal. Fig. 13 compares " $\mathrm{A}$ " phase voltage between PLECS simulation and MagNet simulation with linear and nonlinear silicon steel. It's quite obvious voltage with linear silicon steel matches better with PLECS result than nonlinear silicon steel. Fig. 14 displays the FFT analysis result of the three $u_{a}$ in Fig. 13. It shows nonlinear $\mu$ causes higher THD and lower fundamental voltage than linear $\mu$. It is because nonlinear silicon steel will saturate at high current and corresponding magnetic reluctance will increases and inductance decreases, which means the peak of phase voltage will be suppressed for nonlinear $\mu$. 


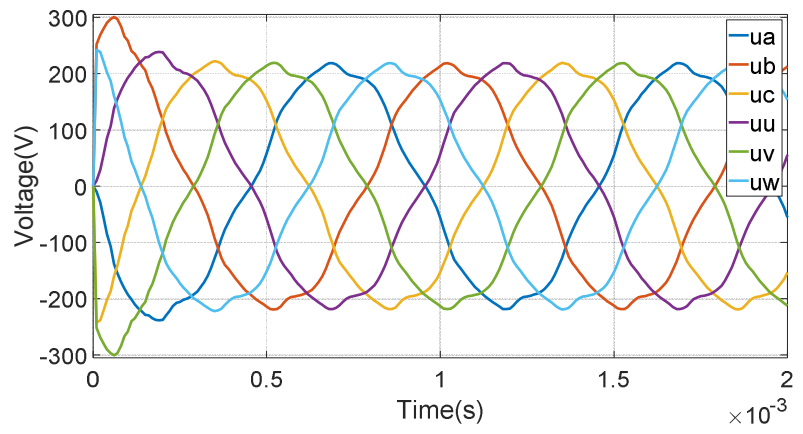

Fig. 12. Six phase voltage obtained from MagNet

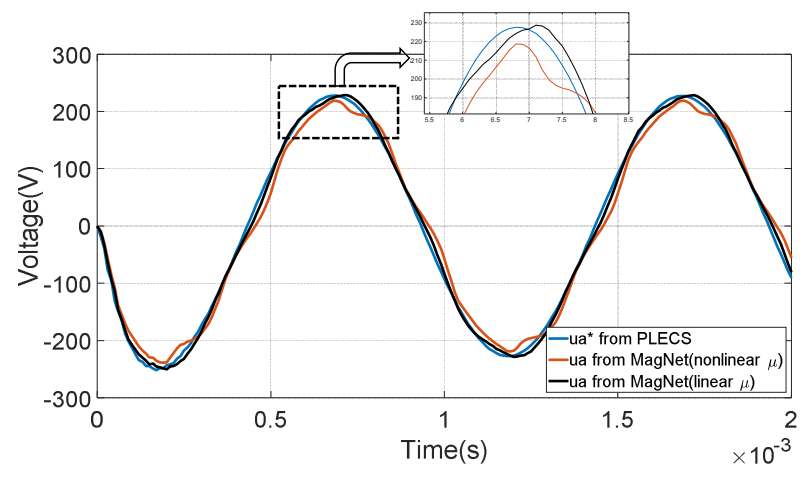

Fig. 13. Comparison of A phase voltage of PLECS and MagNet

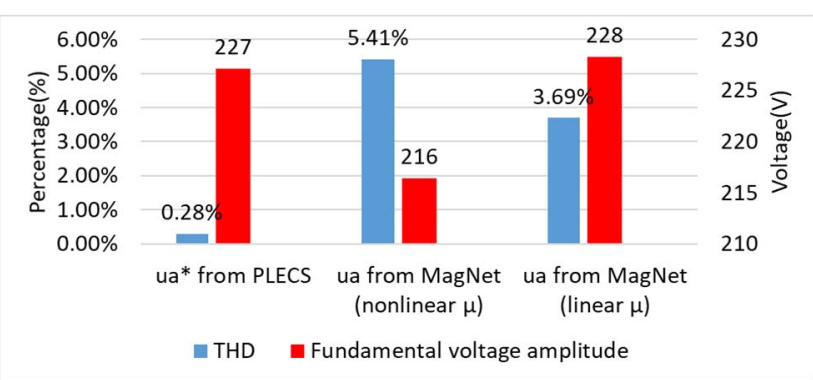

Fig. 14. Voltage THD and Fundamental voltage comparison of A phase between PLCES and MagNet

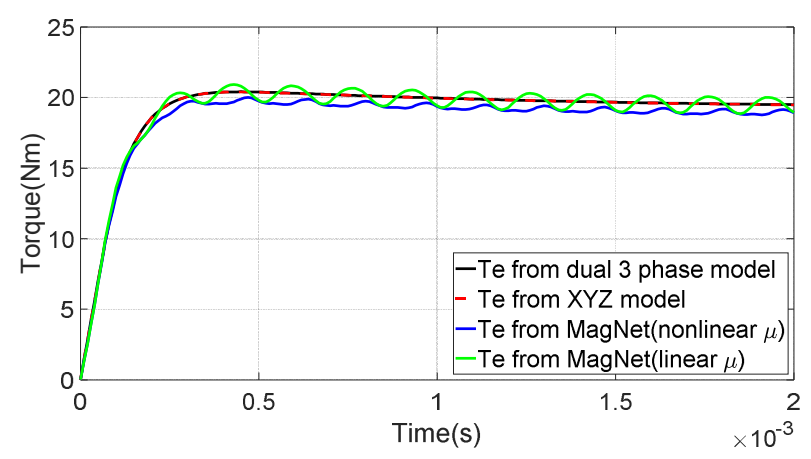

Fig. 15. Torque comparison in PLECS and MagNet

Fig. 15 compares the torque between PLECS simulation and MagNet simulation. The first conclusion is all the torque results are similar, which means the $\mathrm{XYZ}$ model is equivalent with both dual 3 phase model and MagNet model. The second conclusion is that torques from dual 3 phase model and $\mathrm{XYZ}$ model are almost 100\% matched, but have some small difference with MagNet result. Torque for nonlinear $\mu$ has smaller mean but smaller fluctuation than linear $\mu$. For the smaller mean, it is because nonlinear $\mu$ will lead to smaller fundamental voltage and smaller absorbing power. For the smaller fluctuation, it is because the saturation of silicon steel will suppress the back-EMF harmonics.

\section{CONCLUSION}

This paper proposes a modelling method for asymmetrical dual three phase permanent magnet machine. By applying inverse voltage to two sets of windings, the machine can be regarded as a symmetrical three phase model (XYZ model). The XYZ model is a decoupled model and traditional current close loop PI control can be applied to it. Simulation result proves it is equivalent with dual 3 phase machine model as well as finite element model.

\section{ACKNOWLEDGMENT}

This project has received funding from the Clean Sky 2 Joint Undertaking under the European Union's Horizon 2020 research and innovation programme under grant agreement No 737814.

\section{REFERENCES}

[1] Y. Demir and M. Aydin, "Design, analysis and validation of a dual three-phase 72-slot, 12-pole permanent magnet synchronous motor," in 2016 XXII International Conference on Electrical Machines (ICEM), 2016, vol. 52, no. 7, pp. 1598-1603.

[2] P. Xu et al., "Analysis of Dual Three-Phase Permanent-Magnet Synchronous Machines with Different Angle Displacements," IEEE Trans. Ind. Electron., vol. 65, no. 3, pp. 1941-1954, 2018.

[3] Y. Demir and M. Aydin, "A Novel Dual Three-Phase Permanent Magnet Synchronous Motor with Asymmetric Stator Winding," IEEE Trans. Magn., vol. 52, no. 7, pp. 10-14, 2016.

[4] K. Kluszczynski and M. Szczygiel, "Study on 3-winding system with angular asymmetry part I - current zero-components and 2-axis transformation," in 2017 International Symposium on Electrical Machines (SME), 2017, pp. 1-6.

[5] K. Kluszczynski and M. Szczygiel, "Study on 3-winding system with angular asymmetry part II - eigenvalues of inductance matrix and transformation $\alpha \beta 0$," in 2017 International Symposium on Electrical Machines (SME), 2017, no. 3, pp. 1-6.

[6] G. Valente, L. Papini, A. Formentini, C. Gerada, and P. Zanchetta, "Radial Force Control of Multisector Permanent-Magnet Machines for Vibration Suppression," IEEE Trans. Ind. Electron., vol. 65, no. 7, pp. 5395-5405, Jul. 2018.

[7] G. Valente, L. Papini, A. Formentini, C. Gerada, and P. Zanchetta, "Radial force control of multi-sector permanent magnet machines," in 2016 XXII International Conference on Electrical Machines (ICEM), 2016, pp. 2595-2601.

[8] G. Valente, L. Papini, A. Formentini, C. Gerada, and P. Zanchetta, "Open-Circuit Fault Tolerant Study of Bearingless Multi-Sector Permanent Magnet Machines," in 2018 International Power Electronics Conference (IPEC-Niigata 2018 -ECCE Asia), 2018, pp. 4034-4041.

[9] G. Sala et al., "Space Vectors and Pseudoinverse Matrix Methods for the Radial Force Control in Bearingless Multisector Permanent Magnet Machines," IEEE Trans. Ind. Electron., vol. 65, no. 9, pp. 6912-6922, Sep. 2018.

[10] N. Bianchi and M. Dai Pre, "Use of the star of slots in designing fractional-slot single-layer synchronous motors," IEE Proc. - Electr. Power Appl., vol. 153, no. 3, p. 459, 2006. 
[11] M. Barcaro, N. Bianchi, and F. Magnussen, "Faulty Operations of a PM Fractional-Slot Machine With a Dual Three-Phase Winding," IEEE Trans. Ind. Electron., vol. 58, no. 9, pp. 3825-3832, Sep. 2011.

[12] Q. Ni, M. Yang, S. Odhano, M. Tang and et al., " A New Position and Speed Estimation Scheme for Position Control of PMSM Drives
Using Low-resolution Position Sensors," IEEE Trans. Ind. Appl., pp. 1-1, Mar. 2019. 